\title{
Clinical Spectrum of Rheumatic Heart Disease in Pediatric and Adolescent Patients Attending B.S.M.C.H, Bankura: A Rural Tertiary Medical Center in India
}

\section{Sandip Gupta ${ }^{1 *}$, Snehansu Chakraborti ${ }^{2}$ and Kanak Kr. Mitra ${ }^{3}$}

${ }^{1}$ Post Graduate Trainee, Department of Pediatrics, B.S.M.C. \& H, Bankura, WBUHS, India

${ }^{2}$ Professor and Head of Department of Pediatrics, B.S.M.C. \& H, Bankura, WBUHS, India

${ }^{3}$ Professor and Head of Department of Cardiology, B.S.M.C. \& H, Bankura, WBUHS,

India

*Corresponding Author: Sandip Gupta, Post Graduate Trainee, Department of

Pediatrics, B.S.M.C. \& H, Bankura, WBUHS, India.
Received: September 02, 2020

Published: October 16, 2020

(C) All rights are reserved by Sandip Gupta.,

et al.

\begin{abstract}
RHD is a major complication of Rheumatic fever, affecting children and young adults in there most productive years of life, despite found decreasing in the developed world, it is still a major cause of acquired cardiovascular mortality and morbidity in our country. In this study sample was selected randomly from pediatric and adolescent RHD patients aged upto 18 years if they fulfill the inclusion criteria. All the 102 children were first clinically evaluated as per case record form, then undergone serial relevant investigation. Echocardiography (2D, M-MODE and COLOUR-DOPPLER) was done.

Results showed slight male preponderance among the patients, the mean age of patients was $11.43 \pm 3.58$ years, majority of them 85.29\% were from rural areas and belong to low socioeconomic class, history of rheumatic fever in past was present in $38.23 \%$ patients. Most common mode of presentation was heart failure seen in $31.37 \%$ of patients, a significant proportion of patients had recurrence of rheumatic fever (18.62\%), mostly those who were non-compliant to penicillin prophylaxis, pulmonary hypertension was found in $14.7 \%$ of patients. Incidence of other complications such as stroke, infective endocarditis, arrhythmia were low as expected in this age group (upto 18 years), due to the temporal delay in development of complications of RHD.

Isolated mitral valve involvement specially isolated mitral regurgitation was the commonest pattern of involvement. Most common presenting symptom was dyspnoea present in $86.27 \%$ followed by palpitation, fatigue, chest pain, edema. dyspnoea of majority patients was NYHA Class I and II.

Of the studied population $62.74 \%$ received regular prophylaxis and $37.25 \%$ patients had irregular or no prophylaxis. The incidence of heart failure, pulmonary arterial hypertension and recurrence of rheumatic fever was much higher in the latter group.
\end{abstract}

Keywords: Rheumatic Heart Disease (RHD); Acute Rheumatic Fever; Valvular Heart Disease; Infective Endocarditis (IE); Mitral Regurgitation (MR); Mitral Stenosis (MS)

\section{Abbreviations}

RHD: Rheumatic Heart Disease; IE: Infective Endocarditis; ARF: Acute Rheumatic Fever; MR: Mitral Regurgitation; MS: Mitral Ste- nosis; AR: Aortic Regurgitation; AS: Aortic Stenosis; ICMR: Indian Council of Medical Research; ASO: Anti Streptolysin O; CRP: C-Reactive Protein; ESR: Erythrocyte Sedimentation Rate; NYHA: New York Heart Association; WHO: World Health Organization

Citation: Sandip Gupta., et al. "Clinical Spectrum of Rheumatic Heart Disease in Pediatric and Adolescent Patients Attending B.S.M.C.H, Bankura: A Rural Tertiary Medical Center in India”. Acta Scientific Paediatrics 3.11 (2020): 30-36. 


\section{Introduction}

Rheumatic heart disease (RHD) is a major cardiac problem worldwide. Though Rheumatic fever and Rheumatic heart disease have decreased in developed countries, it's still very common in India and many developing countries with its most devastating effects on children and young adults in their most productive years. Acute Rheumatic fever is an immunologically mediated disease following infection with group A beta-hemolytic streptococci, and cardiac manifestations of the disease is known as rheumatic heart disease.

Rheumatic heart disease is the most serious complication of rheumatic fever. Acute rheumatic fever follows $0.3 \%$ of cases of group A beta-hemolytic streptococcal pharyngitis in children. As many as $39 \%$ of patients with acute rheumatic fever may develop varying degrees of pancarditis with associated valve insufficiency, heart failure, pericarditis and even death. With chronic rheumatic heart disease, patients develop valve stenosis with varying degrees of regurgitation, atrial dilation, arrhythmias and ventricular dysfunction. Chronic rheumatic heart disease remains the leading cause of mitral valve stenosis and valve replacement in adults [1,2].

There have been many surveys in India regarding the prevalence of rheumatic heart disease in various parts of the country [3-6]. Even at the beginning of the $21^{\text {st }}$ century [3], the problem of RHD in India has remained the same. ICMR's multi-centric 'Jai Vigyan Mission Mode Project on RF/RHD' was undertaken from 2000 to 2010 to estimate the prevalence of RF/RHD in 176904 school children in the age group of 5 to $14 \mathrm{y}$ at various centre in India. The prevalence of RHD ranged from 0.13 to 1.5 per 1000 in school children in the age group 5 to $9 \mathrm{y}$ and 0.13 to 1.1 per 1000 in the age group of 10 to 14y. There is an apparent decline in RHD prevalence in this study (2000 - 2010) from the earlier ICMR studies conducted in 1970s and 80s [4-6].

A study by Carpentis., et al. estimated that up to 15.6 million people are affected by RHD worldwide [7]. Each year, there are approximately 470,000 new cases diagnosed and 233,000 deaths attributed to RHD [1]. There has not been many a studies on determining the clinical profile and prevalence of different types of RHD in India specially in Eastern India. So, we undertook this study.

\section{Aims and Objectives}

1. To know the profile of various types of valvular involvement in patients with RHD in pediatric and adolescent age group.
2. To determine the spectrum of complications of RHD such as heart failure, arrhythmias, chamber dilation, thrombo-embolic manifestation, pulmonary hypertension and death etc. among those having RHD.

\section{Materials and Methods}

A cross-sectional observational study of 102 Children and adolescent were selected randomly from those attending RHD clinic and admitted in Department of cardiology and Department of Pediatric Medicine with various spectrum of manifestation due to RHD, Bankura Sammilani Medical College and Hospital. Study period extended from February 2013 to July 2014 for a period of 16 months. A predesigned proforma (Annexure I) was used as study tool for documentation of clinical history, clinical examination and various investigations (Echo -doppler study, ECG, Chest Xray, Complete Hemogram. ASO titre, CRP, ESR, Throat swab culture) for Diagnosis and evaluation of RHD and it's various complications.

Echocardiography was done in our cardiology department by Siemens Acuson cv70 echocardiography machine. The other relevant investigations was done in respective department of Bankura Sammilani Medical College and Hospital. Written consent was obtained from parents to participate in the study. An ethical clearance from the Institutional Ethics Committee, was obtained before starting the study (Annexure II). The following Inclusion and exclusion criteria was used for the study.

\section{Inclusion criteria}

1. Age upto18 years.

2. Having a record of a hospital with echocardiographic diagnosis of RHD.

3. Patients having clinical evidence of RHD, later proved by echocardiography.

4. Record of having undergone surgery or balloon valvotomy for RHD.

\section{Exclusion criteria}

1. Age $>18$ years.

2. patients of valvular heart disease of non RHD etiology.

3. Patients not giving consent.

\section{Statistical analysis}

All the accumulated data was analysed by the help of Microsoft mathematics software and Medcalc software. 
Clinical Spectrum of Rheumatic Heart Disease in Pediatric and Adolescent Patients Attending B.S.M.C.H, Bankura: A Rural Tertiary Medical Center in India

\section{Results}

Among the 102 patients studied, 55 were males and 47 were females, male: female ratio being 1.17: 1 .

\begin{tabular}{|c|c|c|c|}
\hline Population & Male & Female & \\
\hline Urban & 9 & 6 & 15 \\
\hline Rural & 46 & 41 & 87 \\
\hline Total & 55 & 47 & 102 \\
\hline
\end{tabular}

Table 1: Demographic distribution of patients.

From table 1 we can see that most of the RHD patients, $85.29 \%$ ( $\mathrm{n}=87$ ) came from Rural area with poor socio-economic background and rest $14.7 \%(\mathrm{n}=15)$ were from urban population. The mean age of the patients was $11.43 \pm 3.58$ years. The youngest patient was 7 years old and the eldest was 18 year old. Mean age of male patients was $11.87 \pm 3.76$ and mean age female patients was $10.91 \pm 3.31$. Females were younger than males.

\begin{tabular}{|c|c|c|}
\hline Socio-economic class & Number & $\mathbf{\%}$ \\
\hline Upper & None & NA \\
\hline Upper middle & 2 & $1.96 \%$ \\
\hline Lower middle & 12 & $11.74 \%$ \\
\hline Upper lower & 23 & $22.55 \%$ \\
\hline Lower & 65 & $63.72 \%$ \\
\hline
\end{tabular}

Table 2: Showing distribution of patients according to socio-economic status.

Table 2 shows that mostly the patients of RHD belonged to lower class $63.72 \%(n=65)$ and upper lower class $22.55 \%(n=23)$. Two patients belonged to upper middle class and 12 were from lower middle class, here no patient from upper class could be shown in this study.

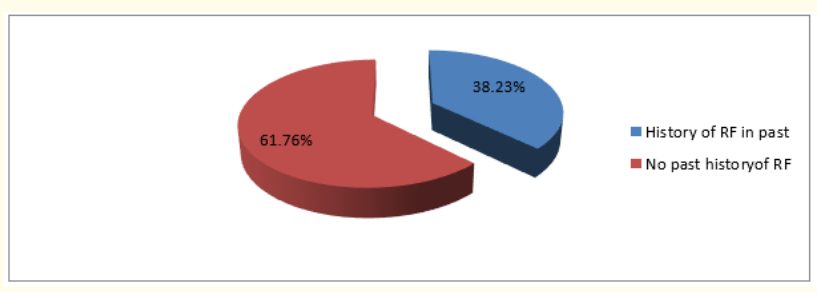

Figure 1: Pie chart showing percentage of patients with history of rheumatic fever in past.
The above figure shows that $38.23 \%(n=39)$ patient had past history of rheumatic fever.

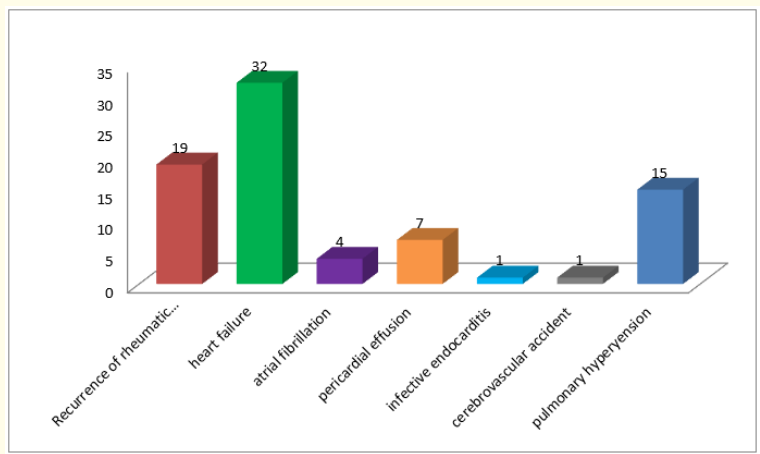

Figure 2: Showing mode of presentation of RHD in study population.

The above bar diagram shows the various mode of presentation of patients, most common mode of presentation was heart failure which was present in 32 (31.37\%) patients, $2^{\text {nd }}$ most common presentation was recurrence of rheumatic fever present in 19 $(18.62 \%)$ patients, pericardial effusion was presents in 7 (6.86\%) patients, atrial fibrillation in $4(3.92 \%)$ patients, cardio-embolic stroke and chorea was seen in $1(0.98 \%)$ each and $15(14.7 \%)$ patient had pulmonary hypertension.

\begin{tabular}{|c|c|c|c|}
\hline Valvular involvement & Male & Female & Total (\%) \\
\hline Isolated MR & 29 & 28 & $57(55.88 \%)$ \\
\hline Isolated MS & 6 & 2 & $8(7.84 \%)$ \\
\hline MS with MR & 6 & 7 & $13(12.74 \%)$ \\
\hline Isolated AR & 2 & 2 & $4(3.9 \%)$ \\
\hline AR with MR & 7 & 8 & $15(14.7 \%)$ \\
\hline AR with MS & 4 & 0 & $4(3.9 \%)$ \\
\hline MR with MS with AR & 1 & 0 & $1(0.98 \%)$ \\
\hline & 55 & 47 & 102 \\
\hline
\end{tabular}

Table 3: Distribution of valvular involvement in study population.

We can see from table 3 that out of 102 patients studied mitral valve involvement (isolated or in combination) was present in 98 (96.07\%) patients. While the aortic valve was affected in 24 $(23.53 \%)$ patients. Out of 102 cases isolated mitral valve involvement was seen in 78 (76.47\%). Most common type of mitral valve involvement was isolated mitral regurgitation (MR). Isolated MR was seen in 57 patients (55.88\% of total study population). Second 
most common of valvular involvement after isolated mitral regurgitation was mitral regurgitation with aortic regurgitation. Isolated mitral stenosis (MS) was seen in 8 patients $(7.84 \%$ of total study population). Combination of mitral stenosis with mitral regurgitation was found in 13 (12.74\% of total population) patients. MR with AR was found in 15 patients out of total 102 study population (14.7\%). Isolated AR was found in 4 patients and one patient had combination of mitral regurgitation and stenosis with aortic regurgitation. And we didn't find any patient who had aortic stenosis or had rheumatic involvement of tricuspid and pulmonary valves. Among the patients with mitral regurgitation $(\mathrm{n}=86)$ (isolated or in combination with stenotic lesion or aortic valve involvement), 17 patients had mild mitral regurgitation, 45 patients had moderate mitral regurgitation and 24 had severe mitral regurgitation.

Among the patients with mitral stenosis (isolated or in combination with mitral or aortic regurgitation) 12 patients had mild MS, 11 had moderate MS and 3 had Severe MS (out of total 26 patients with MS).

Most common presenting symptom of the RHD study population was dyspnea in $88(86.27 \%)$ patients. According to the NYHA functional grading of dyspnea 41 had NYHA grade I, 27 had grade II, and 17 had grade III and 3 had grade IV symptoms. The grade III and IV cases received inpatient treatment. Second most common cardiac manifestation among the study population was palpitation 75 patients. Fatigue was present in 48 and chest pain in 30 patients. Edema was present in 18 patients.

Among the major symptoms of acute or recurrent rheumatic fever; carditis was the most common one seen in 54 patients, arthritis was present in 46 , chorea was seen in a single patient. Also, subcutaneous nodule was present in one patient. And among the minor symptoms; there was a high incidence of a previous history of throat infection in 36 patients while 33 gave a history of fever.

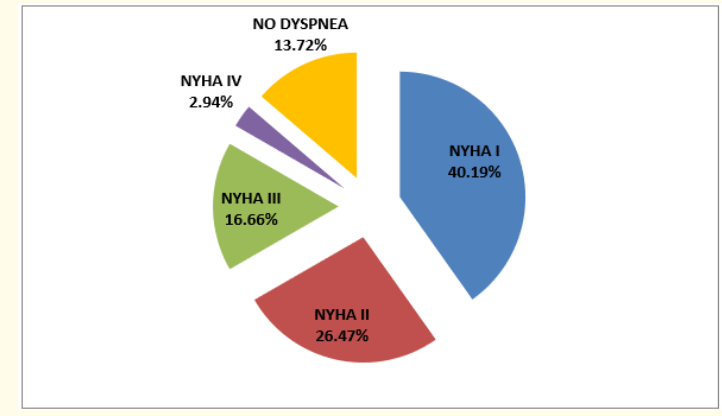

Figure 4: NYHA dyspnea grades among the study population.

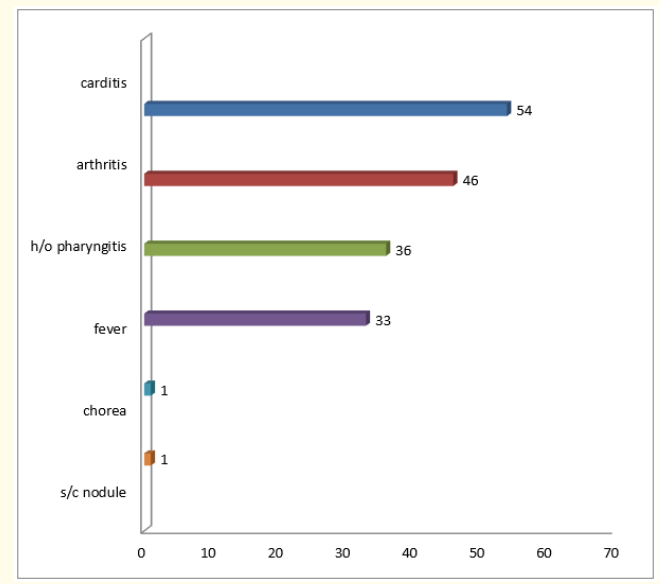

Figure 5: Showing incidence of symptoms of ARF among the study population.

Among the various complications of the rheumatic heart disease, pulmonary hypertension was present in 15 of patients, mostly in elder patients; while 32 developed congestive cardiac failure, only single patient had infective endocarditis, 4 had atrial fibrillation and one patient had cardio-embolic stroke.

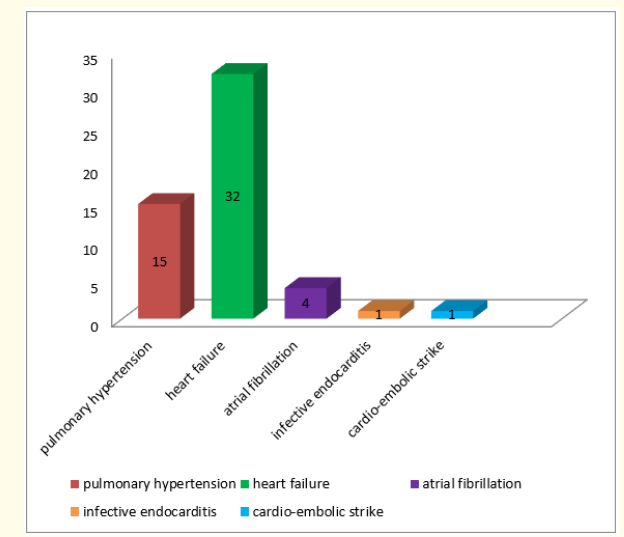

Figure 6: Showing various complications of RHD in study population. 
Regular benzathine penicillin prophylaxis was received by 64 (62.74\%) cases, whereas another $20(19.6 \%)$ took the injections in an irregular manner and the rest 18 (17.64\%) didn't receive any penicillin prophylaxis.

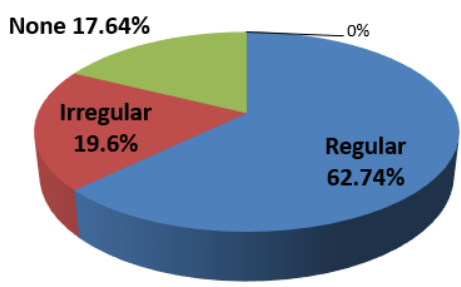

Figure 7: Showing penicillin prophylaxis among study population.

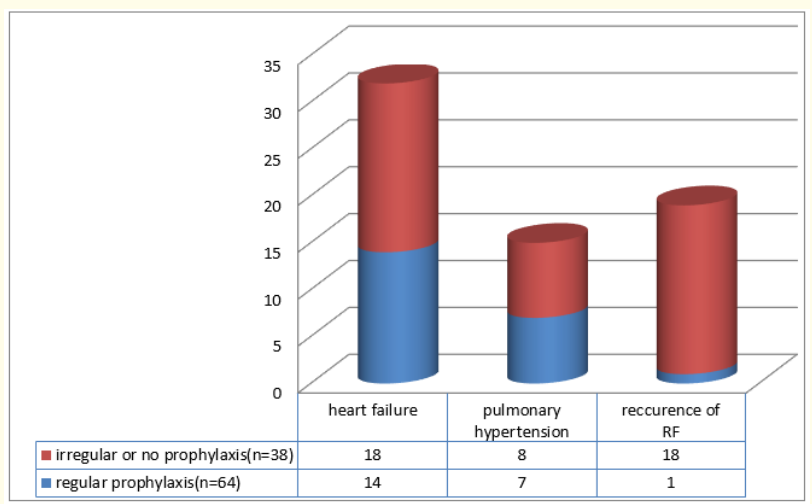

Figure 8: Showing comparison of incidence of complication, between group receiving regular prophylaxis vs irregular or no prophylaxis.

Figure 8 shows that out of those receiving irregular or no prophylaxis (total $=38), 18(47.36 \%)$ had heart failure, $8(21.05 \%)$ had pulmonary hypertension and 18 (47.36\%) had recurrence of rheumatic fever which was much higher than in the patients receiving regular prophylaxis $(n=64)$ in this group $14(21.87 \%)$ had heart failure, 7 (10.93\%) had pulmonary hypertension and only 1 $(0.98 \%)$ had recurrence of rheumatic fever.

\section{Discussion}

Rheumatic heart disease (RHD) has virtually disappeared from the western world; however it continues to be a public health problem in India and several other developing countries. It is a disease of poverty and is associated with overcrowding, poor living con- ditions, poor sanitation and inadequate access to healthcare. The disease affects children and young adolescents causing progressive damage to cardiac valves. According to the World Health Organization (WHO), rheumatic fever (RF)/RHD affects about 15.6 million people worldwide, with 282,000 new cases and 233,000 deaths each year [1]. Deaths result from complication associated with disease such as heart failure, infective endocarditis, cardio-embolic stroke, atrial fibrillation, pulmonary hypertension.

Age of presentation of RHD patients and socio-economic factors: In the present study mean age of the patients was 11.43 \pm 3.58 , the mean age of patients in a study done in Turkey by Ozer OS., et al. [8] was 11.2 years which was similar to our findings. This can be explained high incidence of group A Streptococcal in school going children between age group of 5 year - 15 year and schools are often overcrowded and badly ventilated increasing the spread of Streptococcal infection. In this study most of the patients $86 \%$ belonged to lower and upper lower class, which was similar to studies by Arora R., et al. [9] in New Delhi and Khatoon M., et al. [10] in Bangladesh. Our study also showed that most of patients, $85.29 \%$ were from rural areas, which is similar to work of Radwan A., et al [11]. This can be explained by presence of most of risk factors in poor rural families such as overcrowding, intercurrent infection, protein energy malnutrition, and poor awareness about the disease.

Pattern of valvular involvement: Among the cardiac valvular lesions, mitral valve was found to be the most commonly affected, this was consistent with most other studies [11-13]. The most common valvular pattern was isolated mitral regurgitation, 55.88\% (n $=57)$ the $2^{\text {nd }}$ most common was mitral regurgitation with aortic regurgitation $14.7 \%(n=15)$ followed by mitral regurgitation with mitral stenosis $12.74 \%(\mathrm{n}=13)$ these results were similar to study by Zhang W., et al. [14] showing pure mitral regurgitation was the commonest valvular disease (40.2\%), followed by mitral regurgitation plus aortic regurgitation (29\%). This higher incidence of isolated mitral regurgitation in the present may be explained by the fact that the study population here was patients upto18 years.

Mode of presentation and complications of RHD: The most common mode of presentation was heart failure present in $31.37 \%$ ( $\mathrm{n}=32$ ) patients which is similar to findings of Radwan A., et al. [11] showing $31.1 \%$ and $36.54 \%$ in the study by Ravisha MS., et al [13]. $2^{\text {nd }}$ most common presentation was recurrence of rheumatic fever present in $18.62 \%$ (19) patients in this study, which 
Clinical Spectrum of Rheumatic Heart Disease in Pediatric and Adolescent Patients Attending B.S.M.C.H, Bankura: A Rural Tertiary Medical Center in India

varied among studies, $4.3 \%$ in study by Radwan A., et al. [11] 9.6\% in study by Melka., et al. [15] and 40.7\% in study by Ravisha MS., et al [13]. In this study this was seen that recurrence of rheumatic fever was significantly higher among who were receiving irregular or no prophylaxis than in those receiving regular prophylaxis. It has been found that patients who were compliant and who took regular penicillin prophylaxis rarely had recurrence of RF. In this study $14.7 \%$ patients had pulmonary arterial hypertension, which was lower than that found in other studies, study by Akinwusi OP., et al. [16] showing 36.4\%, and Ogah OS., et al. [17] showing 54.2\%.

Infective endocarditis was present in $0.98 \%(\mathrm{n}=1)$ patients in present study, lower than other studies, 4.6\%, 5.54\% respectively in studies by Radwan A., et al. [11] and Akinwusi OP., et al [16]. Atrial fibrillation was present in $3.92 \%$, which was lower than the other studies, $15.9 \%, 22.2 \%, 27.3 \%$ atrial fibrillation in studies by Ogah OS., et al. [17], Radwan A., et al. [11] and Akinwusi OP., et al. [16] respectively. Pericardial effusion was present $6.86 \%$ in this study lower than that in studies by Bitar FF., et al. [18] finding 11\% pericardial effusion. Stroke was present in $0.98 \%$ in the present study slightly lower than that found in study by Ogah OS., et al. [17] where $2.8 \%$ patients had stroke and much lower than that present in study by Akinwusi OP., et al. [16] where 18.2\% patients had stroke. The lower occurrence of complications in this study may be due the fact that this study included only those patients who were upto 18 years of age and not the older patients and overall complications were expected to be low in this particular age group due to temporal delay in development of complication in RHD patients.

Symptoms of RHD: Most common presenting symptom of the RHD patients in the present study was dyspnoea which was present in $86.27 \%(n=88)$ this was similar to that shown by other studies, $75 \%$ of patients had dyspnoea in study by Zhang W., et al. [14] and77.3\% in study by Thakur JS., et al. [19], another study by Ogah OS., et al. [17] showing 100\% patients having dyspnoea. NYHA (New York Heart Association) Grades of dyspnoea among total patients in this in this study as follows: class I $=40.19 \%$, class II = $26.47 \%$ class III $=16.66 \%$, class IV $=2.94 \%$ this was similar to findings of study by Thakur JS., et al. [19] showing: class I = 38.2\%, class II $=38.2 \%$, class III $=20.6 \%$, class IV $=2.9 \%$, but another study by Zhang W., et al. [14] showing more $43 \%$ having class III and class IV.

All the patients in the present study with class III and class IV required admission. Next most common symptom was palpitation present in $73.53 \%$ of patients in this study. Whereas studies by
Thakur JS., et al. [19] and Zhang W., et al. [14] showed 34.1\% and 95.4\% patients having palpitation respectively. Other symptoms like edema in $17.64 \%$ of patients similar to that shown by Zhang W., et al. [14] showing $14.6 \%$, fatigue in $47.05 \%$ similar to that shown in study by Ogah OS., et al. [17] showing 50.4\%, chest pain in $29.41 \%$ of patients much lesser than that shown by Zhang W., et al. [14] showing $76.4 \%$.

Major features of rheumatic fever: Among the major features of rheumatic fever of rheumatic fever most common was carditis present in $52.94 \%(n=54)$ which is similar to studies by Ravisha MS., et al. [13] showing $42 \%$ patients with carditis. Next most common feature was arthritis present in $45.1 \%(n=46)$, patients, this was similar to that found in study by Khatoon M., et al. [10] and Ravisha MS., et al. [13] showing 64\% and 42\% patients with arthritis respectively. Chorea was found in $0.98 \%(n=1)$ of patients in the present study which is lower than other studies Joseph N., et al. [12] and Ravisha MS., et al. [13] showing $13.7 \%$ and $18.8 \%$ patients with chorea respectively. The lower occurrence of complications in this study may be due the fact that this study included only those patients who were upto 18 years of age and not the older patients, and overall complications were expected to be low in this particular age group due to temporal delay in development of complication in RHD patients.

Penicillin prophylaxis: In this study $62.74 \%(n=64)$ patients received regular prophylaxis which was similar to study by Thakur JS., et al. [19] where $61.4 \%$ patients were receiving regular prophylaxis. It was found that occurrence of major complication such as heart failure, pulmonary hypertension and recurrence of rheumatic fever was higher among who were receiving irregular or no prophylaxis than in those receiving regular prophylaxis.

\section{Conclusion}

Although complication of rheumatic heart disease is expected to be low in pediatric and adolescent (upto 18 years), but this study shows that a significant number of patients of RHD in this age group had to attend hospital for various reasons like Heart failure, recurrence of rheumatic fever, dyspnoea, palpitation, fatigue etc. Demographic profile reveals that it is still prevalent in rural areas and low socio-economic class and non-compliance to penicillin prophylaxis is a major precipitating factor besides poor hygiene, overcrowding and poor nutritional status. Isolated mitral valve involvement specially isolated mitral regurgitation was the commonest valvular involvement in this study, while tricuspid and

Citation: Sandip Gupta., et al. "Clinical Spectrum of Rheumatic Heart Disease in Pediatric and Adolescent Patients Attending B.S.M.C.H, Bankura: A Rural Tertiary Medical Center in India”. Acta Scientific Paediatrics 3.11 (2020): 30-36. 
pulmonary valve involvement are rare and not found in this study. So, some relatively cheap measures like adherence to penicillin prophylaxis, improvement of hygiene and nutritional status, in all diagnosed cases of RHD and rheumatic fever will significantly reduce the morbidity and mortality in this condition.

\section{Conflict of Interest}

None.

\section{Bibliography}

1. World Health Organization. "WHO technical report series no. 923". Rheumatic Fever and Rheumatic Heart Disease (2004).

2. World Health Organization. Seventy-First World Health Assembly. Provisional agenda item 12.8. Rheumatic fever and rheumatic heart disease. Report by the Director-General (2018).

3. Jai Vigyan. "Mission mode project on community control of RHD. Non-communicable diseases". Indian Council of Medical Research Annual Reports (2007): 63-64.

4. Community control of rheumatic fever and rheumatic heart disease. Report of ICMR task force study. New Delhi: Indian Council of Medical Research (1994).

5. Patel DC., et al. "Rheumatic fever and rheumatic heart disease in school children of Anand". The Journal of the Association of Physicians of India 34.12 (1986): 837-839.

6. Avasthi G., et al. "Prevalence survey of rheumatic fever (RF) and rheumatic heart disease (Rhd) in urban and rural school children in Ludhiana". Indian Heart Journal 39.1 (1987): 26.

7. Carapetis Jonathan R., et al. "Acute rheumatic fever". The Lancet 366.9480 (2005): 155-168.

8. Ozer Sema., et al. "Childhood acute rheumatic fever in Ankara, Turkey”. The Turkish Journal of Pediatrics 47.2 (2005): 120124.

9. Arora R. "Clinical profile of rheumatic fever and rheumatic heart disease: a study of 2,500 cases". Indian Heart Journal 33.6 (1981): 264-269.

10. Khatoon M. "Clinical profile of rheumatic fever in some hospitalised children of Bangladesh". Bangladesh Medical Research Council Bulletin 11.1 (1985): 33-38.

11. Radwan A and Bajjey M. "Spotlight on Current Clinical Profile of Rheumatic Heart Diseases (RHD) and Rheumatic Fever (RF) in Sohag University Hospital (Upper Egypt)" (2011).
12. Joseph Nitin., et al. "Clinical spectrum of rheumatic fever and rheumatic heart disease: a 10 year experience in an urban area of South India". North American Journal of Medical Sciences 5.11 (2013): 647.

13. Ravisha MS., et al. "Rheumatic fever and rheumatic heart disease: clinical profile of 550 cases in India". Archives of Medical Research 34.5 (2003): 382-387.

14. Zhang Wanzhu., et al. "Presenting features of newly diagnosed rheumatic heart disease patients in Mulago Hospital: a pilot study". Cardiovascular Journal of Africa 24.2 (2013): 28-33.

15. Melka A. "Rheumatic heart disease in Gondar College of Medial Sciences Teaching Hospital: socio-demographic and clinical profile". Ethiopian Medical Journal 34.4 (1996): 207-216.

16. Akinwusi Patience Olayinka., et al. "The new face of rheumatic heart disease in South West Nigeria”. International Journal of General Medicine 6 (2013): 375.

17. Ogah Okechukwu S., et al. "Chronic rheumatic heart disease in Abeokuta, Nigeria: Data from the Abeokuta heart disease registry". Nigerian Journal of Cardiology 11.2 (2014): 98.

18. Bitar FF., et al. "Rheumatic fever in children: a 15-year experience in a developing country". Pediatric Cardiology 21.2 (2000): 119-122.

19. Thakur Jarnail S., et al. "Epidemiological survey of rheumatic heart disease among school children in the Shimla Hills of northern India: prevalence and risk factors". Journal of Epidemiology and Community Health 50.1 (1996): 62-67.

\section{Assets from publication with us}

- Prompt Acknowledgement after receiving the article

- Thorough Double blinded peer review

- Rapid Publication

- Issue of Publication Certificate

- High visibility of your Published work

Website: www.actascientific.com/

Submit Article: www.actascientific.com/submission.php Email us: editor@actascientific.com

Contact us: +919182824667 